\title{
PENETAPAN INDIKATOR JALAN BERKELANJUTAN
}

\author{
Greece Maria Lawalata \\ Pusat Litbang Jalan dan Jembatan \\ Balitbang Kementerian PUPR \\ Jln. A.H. Nasution 264, Bandung \\ greece.maria@pusjatan.pu.go.id
}

\begin{abstract}
The sustainable road indicator is one of the evaluation tools for sustainable road development, which is an effort to support the Indonesian Government's policy in implementing sustainable development. This paper describes the determination of sustainable road indicators based on sustainable road indicators that have been proposed in previous studies. The step taken is to examine the proposed indicators that are appropriate to be applied in the stages of planning and implementation of road construction and to analyze the interests and ease of applying these indicators. The results of this study indicate that there are 14 sustainable road indicators that can be applied in the stages of construction planning and implementation.
\end{abstract}

Keywords: sustainable development, sustainable roads, road planning, road construction, sustainable road indicators

\begin{abstract}
Abstrak
Indikator jalan berkelanjutan merupakan salah satu perangkat evaluasi pembangunan jalan berkelanjutan, yang merupakan suatu upaya untuk mendukung kebijakan Pemerintah Indonesia dalam mengimplementasikan pembangunan berkelanjutan. Makalah ini menguraikan penentuan indikator jalan berkelanjutan berdasarkan indikator jalan berkelanjutan yang pernah diusulkan pada studi sebelumnya. Langkah yang dilakukan adalah memeriksa usulan indikator-indikator yang sesuai untuk diterapkan pada tahap-tahap perencanaan dan pelaksanaan konstruksi jalan dan melakukan analisis kepentingan dan kemudahan penerapan indikator-indikator tersebut. Hasil studi ini menunjukkan bahwa terdapat 14 indikator jalan berkelanjutan yang dapat diterapkan pada tahap-tahap perencanaan dan pelaksanaan konstruksi.
\end{abstract}

Kata-kata kunci: pembangunan berkelanjutan, jalan berkelanjutan, perencanaan jalan, pelaksanaan konstruksi jalan, indikator jalan berkelanjutan

\section{PENDAHULUAN}

Pembangunan berkelanjutan dimaksudkan untuk memenuhi kebutuhan pada saat ini dan masa mendatang. Jalan sebagai bagian pembangunan dinyatakan pula agar direncanakan dan dilaksanakan dengan memerhatikan prinsip-prinsip berkelanjutan, sesuai dengan Permen PU Nomor 05/PRT/M/2012.

Pembangunan jalan berkelanjutan, sebagai suatu kebijakan Pemerintah, dapat dievaluasi dengan menggunakan indikator-indikator jalan berkelanjutan. Hasil evaluasi jalan berkelanjutan dapat mendorong terciptanya kondisi lingkungan dan ketersediaan sumber daya alam untuk generasi mendatang sesuai prinsip pembangunan berkelanjutan. Selain itu, hasil evaluasi terhadap pembangunan jalan berkelanjutan dapat menjadi suatu laporan kepada dunia bahwa Pemerintah Indonesia telah melaksanakan pembangunan berkelanjutan.

Indikator jalan berkelanjutan adalah suatu alat untuk mengevaluasi kegiatan-kegiatan yang menerapkan prinsip-prinsip berkelanjutan pada pembangunan atau peningkatan jalan. 
Dengan adanya indikator ini, pembangunan jalan tidak mengganggu budaya lokal, atau aspek sosial, tetap terjangkau dan ekonomis, serta tidak mengganggu lingkungan.

Usulan indikator telah ditentukan untuk menggambarkan aspek-aspek sosial, ekonomi, dan lingkungan (Lawalata, 2017). Usulan indikator tersebut dipilih oleh 33 responden yang merupakan ahli jalan, praktisi perencanaan, dan pelaksana jalan yang berasal dari berbagai daerah di Indonesia. Pemilihan indikator dilakukan melalui kuesioner.

Tujuan makalah ini adalah menetapkan indikator jalan berkelanjutan dari usulanusulan indikator jalan berkelanjutan. Indikator yang akan ditetapkan adalah indikator yang sesuai dengan tahapan perencanaan dan tahap pelaksanaan konstruksi jalan serta sesuai pendapat para ahli jalan, yaitu perencana dan pelaksana jalan dari berbagai institusi pemerintah dan swasta.

\section{Usulan Indikator Jalan Berkelanjutan}

Indikator konstruksi berkelanjutan hasil kajian Saparauskas dan Turkis (2006) dari Lithuania berjumlah 6 indikator. Indikator lainnya adalah indikator berkelanjutan proyek infrastruktur hasil kajian Ugwu et al. (2006) berjumlah 55 indikator dan indikator infrastruktur berkelanjutan pada pekerjaan infrastruktur hasil kajian Sanchez dan Lopez (2010) berjumlah 30 indikator. Indikator-indikator tersebut tidak secara langsung menggambarkan pembangunan jalan yang berkelanjutan, tetapi lebih mengarah kepada proyek konstruksi infrastruktur yang berkelanjutan. Jumlah indikator tersebut adalah 91 indikator.

Agar digunakan hanya untuk pekerjaan jalan berkelanjutan, indikator berjumlah 91 indikator yang berkaitan dengan konstruksi infrastruktur berkelanjutan, selanjutnya dipilah agar sesuai dengan tujuan pembangunan, peraturan, dan situasi lapangan, sehingga berjumlah 46 indikator. Dari 46 indikator tersebut, selanjutnya dipilih oleh ahli jalan sebanyak 44 indikator jalan berkelanjutan sebagai usulan indikator jalan berkelanjutan (Lawalata, 2017), seperti yang ditunjukkan pada Tabel 1. Usulan tersebut yang selanjutnya menjadi dasar penelitian ini untuk ditentukan menjadi indikator jalan berkelanjutan.

\section{Teknik-Teknik Penentuan Indikator Berkelanjutan}

Beberapa teknik penentuan indikator konstruksi berkelanjutan dan indikator infrastruktur berkelanjutan ditentukan dengan menggunakan berbagai pendekatan. Sebagai contoh, penentuan dengan menggunakan analisis multikriteria (Saparauskas dan Turskis, 2006), analisis hirarki proses (Sanchez dan Lopez, 2010; Mendoza et al., 1999), dan analisis kuadran (Meetingsift, 2018).

Berbagai literatur menunjukkan bahwa penggunaan skala Likert dalam kuesioner untuk penentuan indikator terlihat lebih mudah untuk dimengerti dan mudah dijawab oleh responden dibandingkan dengan penggunaan analisis hirarki proses. Hal ini berkaitan dengan keterbatasan waktu yang dimiliki responden untuk mengisi kuesioner. 
Tabel 1 Usulan Indikator Jalan Berkelanjutan (Lawalata, 2017)

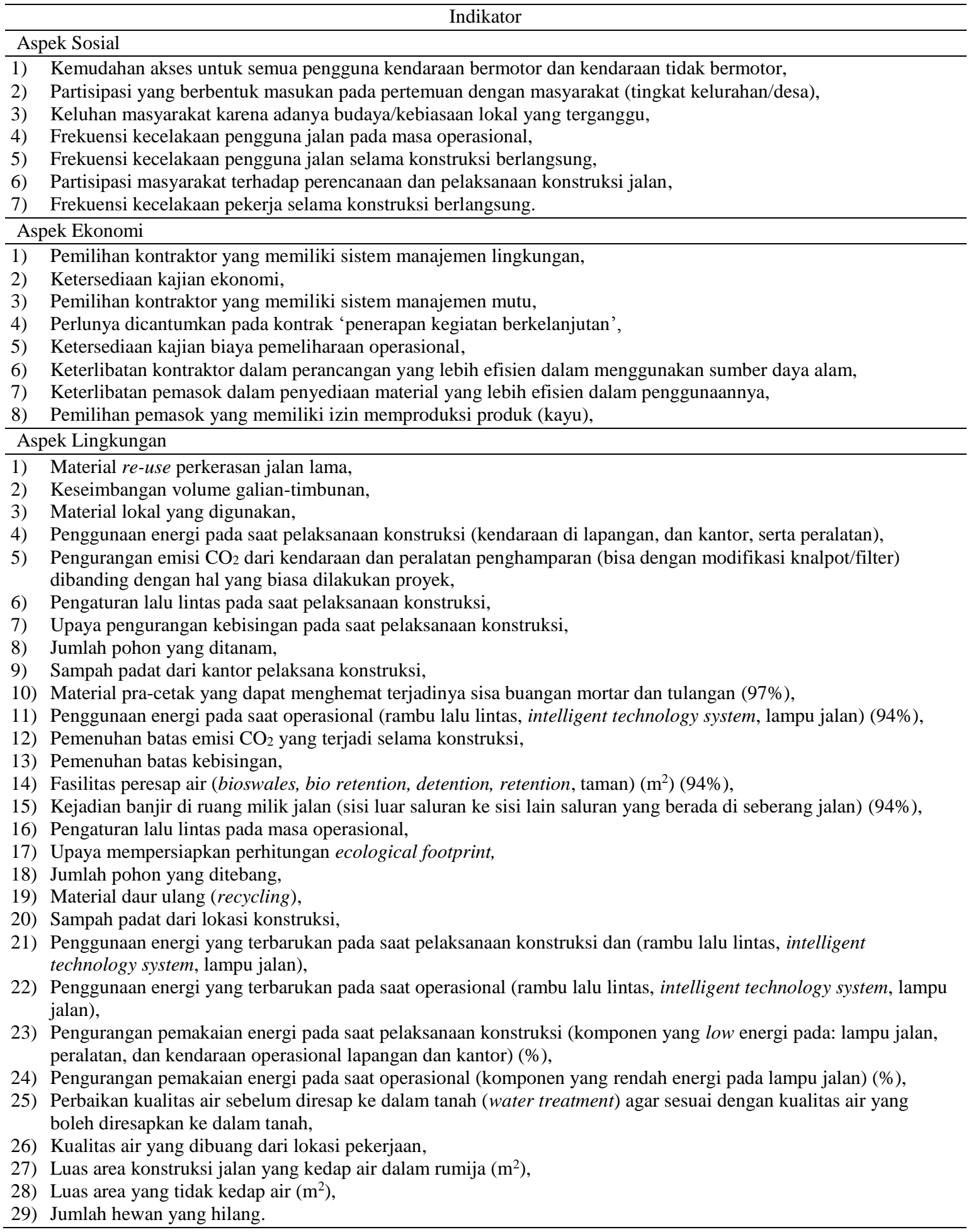

Keterangan: Total usulan indikator jalan berkelanjutan adalah 44 indikator.

\section{METODE PENELITIAN}

Penentuan indikator jalan berkelanjutan yang dapat diterapkan di Indonesia dilakukan dalam beberapa tahap. Tahap pertama adalah pemeriksaan usulan indikator (Lawalata, 2017). 
Usulan indikator diperiksa agar dapat menggambarkan tahap perencanaan dan pelaksanaan konstruksi jalan berkelanjutan. Tahap kedua adalah survei kepentingan dan kemudahan penerapan indikator. Tahap ketiga adalah analisis hasil survei untuk menentukan kemudahan, kepentingan penerapan indikator, dan menetapkan indikator jalan berkelanjutan. Tahap keempat adalah penerapan indikator dan tahap kelima adalah pembahasan, kesimpulan, dan saran.

Pemeriksaan indikator dilakukan agar menggambarkan tahap perencanaan dan tahap pelaksanaan konstruksi jalan berkelanjutan. Setiap indikator dipilih yang menggambarkan tahap perencanaan atau pelaksanaan. Penambahan indikator dilakukan jika terdapat indikator pada tahap perencanaan, tetapi tidak ada pada tahap pelaksanaan konstruksi. Demikian pula sebaliknya, jika indikator ada pada tahap pelaksanaan konstruksi, tetapi tidak ada pada tahap perencanaan, dilakukan penambahan pada tahap perencanaan.

Indikator hasil pemeriksaan selanjutnya diserahkan kepada ahli jalan. Arti kepentingan pada studi ini terkait dengan pentingnya indikator tersebut terhadap keberlanjutan pembangunan jalan dan adanya landasan hukum yang terkait dengan indikator tersebut. Sedangkan kemudahan untuk diterapkan berarti indikator tersebut dapat diimplementasikan walaupun mungkin ada kegiatan tambahan yang harus dilakukan (Sanchez dan Lopez, 2010; Alsulami dan Mohamed, 2011). Pengumpulan pendapat para ahli dilakukan melalui pengiriman kuesioner dengan pilihan jawaban yang menggunakan skala Likert, dengan rentang dari 1 sampai dengan 5. Angka satu berarti sangat tidak setuju, angka dua berarti tidak setuju, angka tiga berarti netral, angka empat berarti setuju, dan angka lima berarti sangat setuju.

Analisis kepentingan dan kemudahan indikator dilakukan berdasarkan pada analisis frekuensi, yaitu respons para responden terhadap kepentingan dan kemudahan penerapan indikator. Respons tersebut akan menentukan prioritas setiap indikator. Frekuensi rata-rata kepentingan dan kemudahan penerapan setiap indikator dihitung dengan menggunakan Rumus 1 (Alsulami dan Mohamed, 2011).

$$
\text { Frekuensi rata-rata }=\frac{(5 x A)+(4 x B)+(3 x C)+(2 x D)+(1 x E)}{(A+B+C+D+E)}
$$

dengan:

$1,2,3,4,5=$ nilai skala Likert,

A, B, C, D, E = jumlah pemilih angka skala Likert.

\section{DATA DAN ANALISIS}

\section{Pemeriksaan Usulan Indikator Jalan Berkelanjutan}

Hasil pemeriksaan usulan indikator jalan berkelanjutan menunjukkan bahwa setiap usulan indikator belum semua dapat diberlakukan untuk setiap tahap perencanaan dan pelaksanaan konstruksi. Untuk itu, perlu dilakukan penggabungan, penambahan, dan pengurangan indikator. Penggabungan indikator dilakukan karena indikator memiliki makna yang sama. Penambahan indikator dilakukan agar indikator dapat menggambarkan keberlanjutan yang menyeluruh terhadap aspek-aspek sosial, ekonomi, dan lingkungan. Pengurangan indikator 
dilakukan karena indikator tersebut dijadikan tanda indikator untuk tahap perencanaan atau pelaksanaan konstruksi.

Pada aspek sosial, indikator yang sebelumnya ada 6 buah, dikurangi menjadi 4 indikator, yaitu penyediaan akses pejalan kaki, pelestarian budaya lokal, ornamen jalan, dan kecelakaan. Indikator yang dikurangi adalah partisipasi masyarakat yang dianggap telah biasa dilakukan dalam dialog-dialog saat perencanaan dan pelaksanaan konstruksi. Keempat indikator tersebut berkaitan dengan kepentingan pemanfaatan jalan oleh masyarakat dan dukungan terhadap peningkatan kualitas hidup masyarakat.

Pada aspek ekonomi, dari 8 indikator diubah menjadi 3 indikator yang mewakili aspek ekonomi, yaitu biaya siklus hidup jalan, kualitas konstruksi, dan kontrak kerja jalan berkelanjutan. Tiga indikator tersebut dianggap dapat mengakomodir 8 indikator yang diusulkan, yaitu gambaran bahwa perencanaan jalan yang baik akan memilih rute jalan, material, dan teknologi yang dihitung ekonomis selama masa layan jalan tersebut (siklus hidup jalan).

Pada aspek lingkungan, dari 27 indikator berkurang menjadi 21 indikator, yang secara garis besar meliputi penghematan material baru, penghematan penggunaan energi, konservasi-konservasi udara, air, dan tanah. Indikator-indikator tersebut adalah penggunaan material (lokal, bongkaran, dan daur ulang), penggunaan bahan bakar minyak yang minimum, teknologi yang hemat energi (saat pelaksanaan konstruksi dan operasional), penggunaan energi terbarukan (saat pelaksanaan konstruksi dan operasional), penggunaan air sisa, fasilitas peresap, persentase luas permukaan kedap, pohon yang ditanam, pelestarian hewan, laporan pelaksanaan pengelolaan pemantauan lingkungan, emisi (alat konstruksi dan kemacetan lalu lintas), kebisingan, perbaikan sisa air, serta sampah konstruksi (dari material baru dan bongkaran serta aspek perubahan iklim). Indikator hasil pemeriksaan ditunjukkan pada Tabel 2.

Tabel 2 Indikator Hasil Pemeriksaan Sesuai Tahap Perencanaan dan Pelaksanaan Konstruksi

\begin{tabular}{|c|c|c|}
\hline \multirow{2}{*}{ Indikator } & \multicolumn{2}{|l|}{ Tahap } \\
\hline & Perencanaan & Pelaksanaan Konstruksi \\
\hline \multicolumn{3}{|l|}{ Aspek Sosial } \\
\hline 2. Pelestarian budaya lokal & $\begin{array}{l}\text { Kegiatan yang menerima masukan dari } \\
\text { masyarakat melalui pertemuan masyarakat }\end{array}$ & $\begin{array}{l}\text { Tidak menghentikan } \\
\text { budaya, contoh perayaan } \\
\text { hari padi }\end{array}$ \\
\hline 3. Ornamen jalan & Perencanaan ornamen jalan & Pelaksanaan ornamen \\
\hline $\begin{array}{l}\text { 4. Kecelakaan pekerja dan pengguna } \\
\text { jalan }\end{array}$ & Audit keselamatan jalan tahap perencanaan & $\begin{array}{l}\text { Laporan mingguan yang } \\
\text { jika ada catatan } \\
\text { kecelakaan pekerja dan } \\
\text { pengguna jalan }\end{array}$ \\
\hline $\begin{array}{l}\text { 6. Kualitas konstruksi sesuai kebutuhan } \\
\text { beban lalu lintas }\end{array}$ & $\begin{array}{l}\text { Perencanaan konstruksi yang sesuai dengan } \\
\text { kebutuhan }\end{array}$ & $\begin{array}{l}\text { Sertifikat sistem } \\
\text { manajemen mutu yang } \\
\text { menunjukkan pelaksana } \\
\text { mengetahui penjagaan } \\
\text { mutu konstruksi }\end{array}$ \\
\hline 7. Kontrak kerja jalan berkelanjutan & $\begin{array}{l}\text { Kontrak yang mencantumkan pekerjaan } \\
\text { jalan berkelanjutan }\end{array}$ & $\begin{array}{l}\text { Kontraktor memiliki } \\
\text { sertifikat manajemen } \\
\text { lingkungan dan sertifikat } \\
\text { manajemen kesehatan dan } \\
\text { keselamatan kerja }\end{array}$ \\
\hline
\end{tabular}


Tabel 2 Indikator Hasil Pemeriksaan Sesuai Tahap Perencanaan dan Pelaksanaan Konstruksi (lanjutan)

\begin{tabular}{|c|c|c|}
\hline \multirow{2}{*}{ Indikator } & \multicolumn{2}{|c|}{ Tahap } \\
\hline & Perencanaan & Pelaksanaan Konstruksi \\
\hline \multicolumn{3}{|l|}{ Aspek Lingkungan } \\
\hline 8. Penggunaan material lokal & Perencanaan penggunaan material lokal & $\begin{array}{l}\text { Pelaksanaan penggunaan } \\
\text { material lokal tersebut }\end{array}$ \\
\hline $\begin{array}{l}\text { 9. Material bongkaran dari areal } \\
\text { konstruksi yang digunakan kembali }\end{array}$ & $\begin{array}{l}\text { Perencanaan penggunaan kembali material } \\
\text { bongkaran }\end{array}$ & $\begin{array}{l}\text { Penggunaan material } \\
\text { bongkaran }\end{array}$ \\
\hline 10. Material daur ulang & $\begin{array}{l}\text { Perencanaan penggunaan material daur } \\
\text { ulang }\end{array}$ & $\begin{array}{l}\text { Penggunaan material daur } \\
\text { ulang }\end{array}$ \\
\hline $\begin{array}{l}\text { 11. Penggunaan bahan bakar minyak } \\
\text { pada peralatan dan kendaraan } \\
\text { konstruksi sebagai bentuk } \\
\text { penghematan bahan bakar minyak }\end{array}$ & $\begin{array}{l}\text { Pendataan penggunaan bahan bakar pada } \\
\text { peralatan dan kendaraan }\end{array}$ & $\begin{array}{l}\text { Jumlah peralatan dan } \\
\text { kendaraan yang } \\
\text { menggunakan bahan } \\
\text { bakar minyak }\end{array}$ \\
\hline $\begin{array}{l}\text { 12. Penggunaan komponen/teknologi } \\
\text { hemat energi saat pelaksanaan }\end{array}$ & $\begin{array}{l}\text { Perencanaan komponen/teknologi yang } \\
\text { dapat menghemat energi }\end{array}$ & Perencanaan dilaksanakan \\
\hline
\end{tabular}
hemat energi saat pelaksanaan konstruksi

13. Penggunaan komponen/teknologi hemat energi yang digunakan pada tahap operasional

14. Energi terbarukan saat pelaksanaan konstruksi

15. Energi terbarukan yang digunakan pada saat operasional

16. Penggunaan air sisa yang digunakan

17. Fasilitas peresap air permukaan di rumija

18. Persentase luas permukaan kedap/ tidak kedap air

19. Pohon yang ditanam

20. Pelestarian hewan

21. Laporan Pelaksanaan Pengelolaan dan Pemantauan Lingkungan

22. Emisi dari peralatan konstruksi yang terjadi

23. Emisi dari kemacetan lalu lintas pada saat pelaksanaan konstruksi

24. Kebisingan yang terjadi

25. Perbaikan sisa air yang digunakan untuk diresapkan ke tanah/dibuang ke badan air

26. Sampah konstruksi dari material baru dan alat yang dipakai yang diminimumkan

dapat menghemat energi

Perencanaan komponen/teknologi yang dapat menghemat energi

Pelaksanaan perencanaan

Perencanaan komponen/teknologi yang menggunakan energi terbarukan

Perencanaan komponen/teknologi yang menggunakan energi terbarukan

Perencanaan penggunaan jumlah air

Perencanaan fasilitas peresap air permukaan

Perencanaan persentase luas permukaan kedap air

Perencanaan penanaman pohon

Perencanaan pelestarian hewan akibat adanya jalan, sebagai contoh perlintasan hewan seperti kabel perlintasan tupai atau gorong-gorong perlintasan kadal

Perencanan yang mencantumkan hasil dari hasil analisis dampak lingkungan dari amdal/UKL dan UPL/SPPL

Perencanaan pengurangan emisi, contoh dengan modifikasi knalpot satu atau lebih peralatan konstruksi

Perencanaan pengurangan emisi dengan pengaturan lalu lintas seperti pengalihan rute dan rambu lalu lintas sementara Perencanaan pengurangan kebisingan agar sesuai dengan ambang yang ditetapkan seperti dengan membuat bangunan peredam bising atau pengalihan rute lalu lintas jika lalu lintas yang menyebabkan kebisingan Perencanaan perangkat untuk memperbaiki sisa air

Perencanaan penggunaan jenis material pracetak atau pencampuran di tempat

Pelaksanaan perencanaan

Pelaksanaan perencanaan

Pelaksanaan perencanaan

Pelaksanaan perencanaan

Pelaksanaan perencanaan

Pelaksanaan perencanaan

Pelaksanaan perencanaan

Pelaksanaan perencanaan

Pelaksanaan perencanaan

Pelaksanaan perencanaan

Pelaksanaan perencanaan

Perencanaan penggunaan bongkaran konstruksi lama

Perencanaan penanganan drainase permukaan sesuai kebutuhan

Pelaksanaan perencanaan

Pelaksanaan perencanaan

Pelaksanaan perencanaan

Pelaksanaan perencanaan

28. Aspek perubahan iklim, yaitu penanganan air hujan yang diantisipasi dengan desain sistem drainase jalan 


\section{Analisis Kepentingan dan Kemudahan Penerapan Indikator Jalan Berkelanjutan}

Hasil survei kepentingan dan kemudahan penerapan indikator oleh responden (Tabel 3) menunjukkan bahwa semua indikator umumnya dianggap penting dalam pekerjaan jalan. Indikator-indikator tersebut tidak semua mudah diterapkan. Namun demikian, nilai Frpi dan nilai Frmi menunjukkan nilai lebih besar daripada 3, yang berarti umumnya indikatorindikator tersebut penting dan mudah diterapkan.

Nilai-nilai Frpi dan Frmi setiap indikator jalan berkelanjutan diplot pada grafik. Termasuk dua garis yang menunjukkan nilai Frpi rata-rata $(4,44)$ dan garis yang menunjukkan nilai Frmi rata-rata $(3,75)$. Ringkasan perhitungan ditunjukkan pada Tabel 3.

Tabel 3 Indikator dan Frekuensi Kepentingan dan Kemudahan

\begin{tabular}{|c|c|}
\hline No. & Indikator; Frpi; Frmi; Kuadran \\
\hline & Aspek Sosial \\
\hline 1 & $\begin{array}{l}\text { Penyediaan akses pejalan kaki pada saat pelaksanaan konstruksi yang ditandai dengan rambu } \\
\text { sementara; } 4,50 ; 3,97 ; \mathrm{PM}\end{array}$ \\
\hline 2 & Budaya lokal yang dilestarikan; 3,94; 3,67; TPTM \\
\hline 3 & Ornamen jalan yang menarik; 4,11;3,94; TPM \\
\hline \multirow[t]{2}{*}{4} & Kecelakaan pekerja dan pengguna jalan; 4,58; 4,08; PM \\
\hline & Aspek Ekonomi \\
\hline 5 & Laporan biaya siklus hidup jalan; 4,50; 3,75; PM \\
\hline 6 & Kualitas konstruksi sesuai kebutuhan beban lalu lintas; 4,81; 4,31; PM \\
\hline \multirow[t]{2}{*}{7} & Kontrak kerja mencantumkan pekerjaan jalan sebagai jalan berkelanjutan; 4,39; 3,86; TPM \\
\hline & Aspek Lingkungan \\
\hline 8 & Penggunaan material lokal; 4,56; 3,97; PM \\
\hline 9 & Material bongkaran dari areal konstruksi yang digunakan kembali; 4,47; 3,78; PM \\
\hline 10 & Material daur ulang; 4,33; 3,69; TPTM \\
\hline 11 & $\begin{array}{l}\text { Penggunaan bahan bakar minyak pada peralatan dan kendaraan konstruksi sebagai bentuk } \\
\text { penghematan bahan bakar minyak; 4,06; 3,56; TPTM }\end{array}$ \\
\hline 12 & Penggunaan komponen/teknologi hemat energi saat pelaksanaan konstruksi; 4,47; 3,83; PM \\
\hline 13 & $\begin{array}{l}\text { Penggunaan komponen/teknologi hemat energi yang digunakan pada tahap operasional; } 4,67 ; 3,81 ; \\
\text { PM }\end{array}$ \\
\hline 14 & Energi terbarukan saat pelaksanaan konstruksi (termasuk inovasi); 4,47; 3,19; PTM \\
\hline 15 & Energi terbarukan yang digunakan pada jalan; 4,19; 3,33; TPTM \\
\hline 16 & Sisa penggunaan air yang digunakan; 4,$56 ; 3,75 ; \mathrm{PM}$ \\
\hline 17 & Fasilitas peresap air permukaan di rumija; 4,$56 ; 3,81 ; \mathrm{PM}$ \\
\hline 18 & Persentase luas permukaan kedap/tidak kedap air; 4,42; 3,75; TPM \\
\hline 19 & Pohon yang ditanam; 4,61; 4,11; PM \\
\hline 20 & Pelestarian hewan; 4,17; 3,31; TPTM \\
\hline 21 & Laporan Pelaksanaan Pengelolaan dan Pemantauan Lingkungan; 4,56; 3,86; PM \\
\hline 22 & $\begin{array}{l}\text { Emisi dari peralatan konstruksi yang terjadi pada peralatan konstruksi seperti asphalt mixing asphalt, } \\
\text { kendaraan molen, truk, dan mesin penghampar; 4,39; 3,50; TPTM }\end{array}$ \\
\hline 23 & Emisi dari kemacetan lalu lintas pada saat pelaksanaan konstruksi; 4,54; 3,50; PTM \\
\hline 24 & Kebisingan yang terjadi; 4,$44 ; 3,61 ;$ PTM \\
\hline 25 & $\begin{array}{l}\text { Perbaikan sisa air yang digunakan untuk diresapkan ke tanah/dibuang ke badan air; 4,28; 3,61; } \\
\text { TPTM }\end{array}$ \\
\hline 26 & Sampah konstruksi dari material baru dan alat yang dipakai; 4,56; 3,81; PM \\
\hline 27 & Sampah konstruksi dari bongkaran konstruksi lama; 4,50; 3,67; PTM \\
\hline 28 & $\begin{array}{l}\text { Aspek perubahan iklim, yaitu penanganan air hujan yang diantisipasi dengan desain sistem drainase } \\
\text { jalan; } 4,81 ; 4,08 ; \text { PM }\end{array}$ \\
\hline
\end{tabular}

Keterangan: PM = penting dan mudah diterapkan; PTM = penting dan tidak mudah diterapkan; TPM = tidak penting dan mudah diterapkan; TPTM = tidak penting dan tidak mudah diterapkan. 


\section{PEMBAHASAN}

\section{Analisis Usulan Indikator Jalan Berkelanjutan}

Usulan indikator-indikator jalan berkelanjutan (44 buah) yang disampaikan oleh Lawalata (2017) merupakan gambaran indikator jalan berkelanjutan yang belum menunjukkan penggunaan indikator pada tahap perencanaan atau pelaksanaan konstruksi. Dengan melakukan pemilahan, indikator dipilih sesuai dengan tahapan perencanaan dan pelaksanaan konstruksi. Dengan pemilihan sesuai tahap pelaksanaan konstruksi, indikator-indikator tersebut lebih mudah untuk diterapkan oleh penyelenggara jalan.

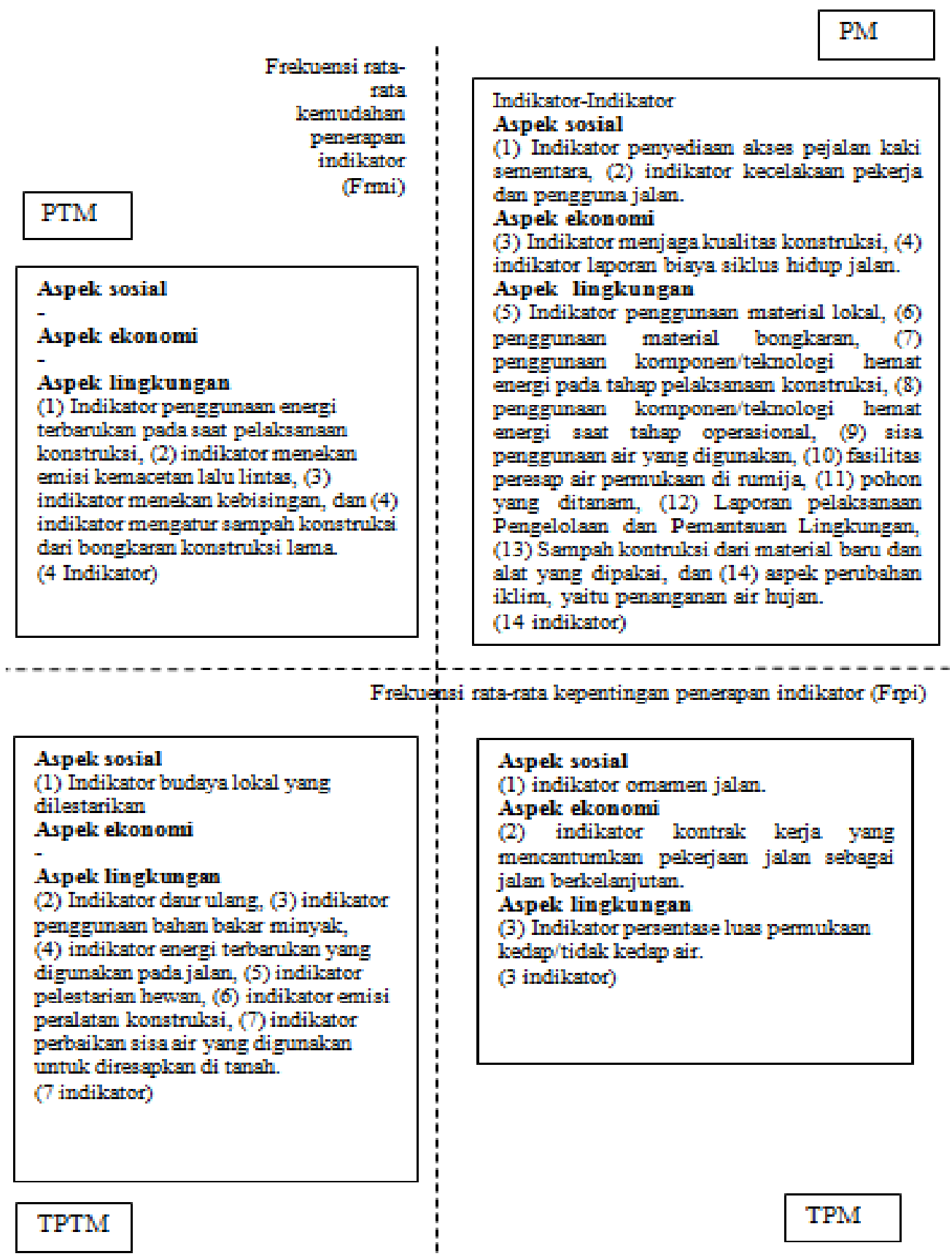

Gambar 1 Hasil Analisis Kuadran 
Penambahan dan pengurangan indikator dilakukan terhadap penggunaan-penggunaan material, energi, serta pelaksanaan konservasi air, udara, dan tanah. Dengan demikian, dilakukan penambahan indikator-indikator untuk meningkatkan kualitas hidup manusia dan mendorong perencanaan dan pelaksanaan konstruksi yang ekonomis, sehingga jumlah indikator menjadi 28 buah.

\section{Analisis Kepentingan dan Kemudahan Penerapan Indikator Jalan Berkelanjutan}

Setelah proses pemeriksaan usulan indikator jalan berkelanjutan, terlihat bahwa pada setiap tahap perencanaan dan pelaksanaan konstruksi terdapat indikator yang harus dicapai. Indikator-indikator tersebut perlu dikaji lebih lanjut dengan menggunakan analisis kepentingan dan kemudahan untuk diterapkan.

Indikator-indikator yang memiliki nilai tidak penting dan/atau nilai yang tidak mudah untuk diterapkan, terletak pada kuadran TPTM, tidak ditetapkan menjadi indikator jalan berkelanjutan. Pada kuadran ini terdapat beberapa indikator, seperti emisi yang terjadi dari peralatan konstruksi dianggap relatif tidak mengganggu lingkungan, pelestarian hewan yang dianggap tidak penting karena hanya terjadi pada kasus-kasus tertentu saja ketika pembangunan jalan melewati area yang memiliki hewan-hewan yang dilindungi, dan perbaikan sisa air yang digunakan untuk diresapkan kembali ke tanah memiliki jumlah yang tidak signifikan untuk diperbaiki dan diresapkan ke dalam tanah.

Indikator lainnya yang disadari penting, namun tidak mudah diterapkan terletak pada kuadran PTM. Indikator pada kuadran tersebut meliputi emisi yang berasal dari kemacetan lalu lintas pada saat pelaksanaan konstruksi yang dianggap tidak penting karena jumlahnya relatif sedikit dan tidak mengganggu kualitas udara di sekitarnya, kebisingan yang dianggap tidak mudah untuk diterapkan karena memerlukan alat uji kebisingan, dan perbaikan sampah konstruksi yang berasal dari material baru dan dari peralatan konstruksi.

\section{Penentuan Indikator Jalan Berkelanjutan}

Hasil pemeriksaan terhadap 44 usulan indikator jalan berkelanjutan (Lawalata, 2017) agar dapat menggambarkan berbagai tahap perencanaan dan tahap pelaksanaan konstruksi, menyebabkan jumlah indikator tersebut berubah menjadi 28. Keduapuluh delapan indikator ini dipilih karena oleh responden dianggap penting dan mudah untuk diterapkan. Dengan menggunakan analisis kuadran diperoleh 14 indikator yang berada di atas rata-rata anggapan penting dan mudah untuk diterapkan, seperti yang disajikan pada Tabel 4.

Keempatbelas indikator dari 28 indikator yang diperiksa menunjukkan bahwa indikator tersebut tetap menggambarkan aspek-aspek sosial, ekonomi, dan lingkungan. Hal ini berarti bahwa keempatbelas indikator tersebut telah sesuai dengan kebijakan pemerintah yang mendorong agar pembangunan dilaksanakan sesuai aspek-aspek sosial, ekonomi, dan lingkungan atau aspek berkelanjutan.

Jumlah indikator jalan berkelanjutan yang ditetapkan adalah 14. Indikator tersebut meliputi 2 indikator pada aspek sosial, 2 indikator pada aspek ekonomi, dan 10 indikator pada aspek lingkungan. Indikator-indikator tersebut merupakan indikator yang telah ringkas 
dan diusulkan harus ada pada perencanaan dan pelaksanaan konstruksi jalan yang berkelanjutan.

Tabel 4 Indikator Jalan Berkelanjutan

\begin{tabular}{l}
\hline \multicolumn{1}{c}{ Indikator } \\
\hline Aspek Sosial \\
\hline 1. Kecelakaan pekerja dan pengguna jalan. \\
2. Penyediaan akses pejalan kaki pada saat pelaksanaan konstruksi yang ditandai dengan rambu sementara. \\
\hline Aspek Ekonomi \\
\hline 3. Kualitas konstruksi sesuai beban lalu lintas. \\
4. Laporan biaya siklus hidup jalan. \\
\hline Aspek Lingkungan \\
\hline 5. Aspek perubahan iklim, yaitu penanganan air hujan yang diantisipasi dengan desain sistem drainase jalan. \\
6. Sisa penggunaan air yang digunakan diperbaiki sebelum diresapkan ke tanah (perbaikan sisa penggu- \\
naan air sebelum diresapkan ke tanah). \\
7. Fasilitas peresap air permukaan di rumija. \\
8. Penggunaan komponen/teknologi hemat energi yang digunakan pada tahap operasional. \\
9. Penggunaan komponen/teknologi hemat energi saat pelaksanaan konstruksi. \\
10. Pohon yang ditanam? \\
11. Penggunaan material lokal. \\
12. Material bongkaran dari areal konstruksi yang digunakan kembali. \\
13. Laporan Pelaksanaan Pemantauan Lingkungan. \\
14. Sampah konstruksi dari material baru dan alat yang dipakai yang diminimumkan? (peminimuman \\
sampah konstruksi).
\end{tabular}

\section{KESIMPULAN DAN SARAN}

Dari penelitian ini dapat disimpulkan bahwa hasil pemeriksaaan terhadap usulan indikator jalan berkelanjutan yang berjumlah 44, terdapat 28 indikator yang sesuai untuk tahap-tahap perencanaan dan pelaksanaan konstruksi jalan. Indikator-indikator tersebut telah mencakup aspek-aspek sosial, ekonomi, dan lingkungan.

Hasil pemeriksaan yang melibatkan para ahli jalan, yaitu perencana dan pelaksana jalan dari berbagai institusi pemerintah dan swasta, diperoleh bahwa sebagian indikator yang dapat diterapkan. Para ahli jalan berpendapat bahwa hanya 14 indikator yang dinilai penting dan mudah untuk diterapkan.

Keempatbelas indikator yang penting dan mudah untuk diterapkan meliputi aspekaspek sosial, ekonomi, dan lingkungan. Indikator aspek sosial adalah kecelakaan dan akses pejalan kaki, indikator aspek ekonomi adalah kualitas konstruksi dan biaya siklus hidup, sedangkan indikator aspek lingkungan adalah sistem drainase jalan, perbaikan sisa penggunaan air, peresap air, komponen/teknologi hemat energi pada tahap operasional, komponen/ teknologi hemat energi pada tahap pelaksanaan konstruksi, pohon, material lokal, penggunaan kembali material bongkaran, pelaksanaan pemantauan lingkungan, serta peminimuman sampah konstruksi.

Usulan indikator jalan berkelanjutan yang telah diperiksa dan ditinjau dari segi kemudahan penerapannya perlu diujicoba di lapangan sehingga dapat diperoleh gambaran kemudahan penerapannya di lapangan. Selain itu, agar memudahkan penerapan indikator- 
indikator jalan berkelanjutan, perlu disiapkan beberapa hal, seperti tata cara dan teknologi penerapan indikator-indikator tersebut.

\section{UCAPAN TERIMAKASIH}

Makalah ini merupakan pengembangan disertasi penulis pada saat menyelesaikan Program Doktor Ilmu Teknik Sipil, Universitas Katolik Parahyangan, Bandung. Penulis menyampaikan terimakasih kepada seluruh pihak yang telah membantu dalam penulisan makalah sampai diterbitkan. Secara khusus ucapan terimakasih disampaikan kepada Prof. Wimpy Santosa, Ph.D., Prof. Ade Sjafrudin, Ph.D., Bapak Hikmat Iskandar, Ph.D., dan Bapak Ir. Agus Bari Sailendra, M.Sc. yang membantu mengarahkan penelitian ini.

\section{DAFTAR PUSTAKA}

Alsulami, B. dan Mohamed, S. 2011. Key Sustainability Indikators for Infrastructure Systems: An Australian Perspective. Sixth International Conference on Construction in the 21st Century (CITC-VI). Construction Challenges in the New Decade. Kuala Lumpur, Malaysia, July 5-7 2011, 1133-1140. (Online), (http://www.citcglobal.com/ files/114006686.pdf., diakses 13 Desember 2015).

Kementerian Pekerjaan Umum. 2012. Peraturan Menteri Pekerjaan Umum Nomor 05/PRT/ M/2012 tentang Pedoman Penanaman Pohon pada Sistem Jaringan Jalan. Jakarta.

Lawalata, G.M. 2017. Usulan Indikator Jalan Berkelanjutan. Jurnal Jalan dan Jembatan, Pusat Litbang Jalan dan Jembatan. Bandung.

Meetingsift. 2018. Quadrant Analysis for Strategic Decision Making, Try This MeetingShift Functionality. (Online), (http://meetingsift.com/quadrant-analysis/\#sub_menu1, diakses 8 Januari 2018).

Mendoza, G.A., Macoun, P., Prabhu, R., Sukadri, D., Purnomo, H., dan Hartanto, H. 1999. Panduan untuk Menerapkan Analisis Multikriteria dalam Menilai Kriteria dan Indikator: Sembilan Perangkat Kriteria dan Indikator. Center for International Forestry Research (CIFOR) bekerjasama dengan The European Commission-Deutsche Gesellschaft fur Technische Zusammenarbeit (GTZ) GmbH Eschorn-United States Agency for International Development (USAID) Washington, (Online), (www.cifor.org, diakses 5 Mei 2017).

Sanchez, G.F. dan Lopez. F.R. 2010. A Methodology to Identify Sustainability Indicators in Construction Project Management: Application to Infrastructure Projects in Spain. Journal Ecological Indikators, 10. (Online), (www.elsevier.com/locate/ecolind, diakses 15 Januari 2016).

Saparauskas, J. dan Turskis, Z. 2006. Evaluation of Construction Sustainability by Multiple Criteria Methods. Journal of Ukio Technologinis Ir Ekonominis Vystymas Technolo- 
gical and Economic Development of Economy, XII (4). (Online). (http://dx.doi.org, diakses 14 Januari 2016).

Ugwu, O.O., Kumaraswamy, M.M., dan Wong, S.T.Ng. 2006. Sustainability Appraisal in Infrastructure Projects (SUSAIP) Part 1: Development of Indicators and Computational Methods. Journal of Automation in Construction, 15. (Online), (www.elsevier. com, diakses 15 Januari 2016). 